\title{
In Vitro Bioactivity and Cytotoxicity of Chemically Treated Glass Fibers
}

\author{
Ângela Leão Andrade ${ }^{\mathrm{a} *}$, Regina Maria de Marco Turchetti-Maia ${ }^{\mathrm{b}}$, \\ Míriam Teresa Paz Lopes ${ }^{\mathrm{b}}$, Carlos Edmundo Salas ${ }^{\mathrm{c}}$, Rosana Zacarias Domingues ${ }^{\mathrm{a}}$ \\ Departments of ${ }^{\mathrm{a} C h e m i s t r y}$ - ICEx, ${ }^{\mathrm{b}}$ Pharmacology, \\ ${ }^{\mathrm{c} B i o c h e m i s t r y}$ and Imnunology \\ ICB, Universidade Federal de Minas Gerais \\ Av. Antônio Carlos, 6627, 31270-090, Belo Horizonte - MG, Brazil
}

Receveid: October 29, 2003; Revised: 20/05/04

\begin{abstract}
Samples of a commercial glass fiber $\mathrm{FM}^{\circledast}$ (Fiber Max) were used to test the efficacy of a chemical sol-gel surface treatment to enhance their bioactivity. After treatment with tetraethoxysilane (TEOS), individual fiber samples were soaked into a simulated body fluid (SBF) solution, from which they were removed at intervals of 5 and 10 days. Micrographs obtained by scanning electron microscopy (SEM) analysis of samples chemically treated with TEOS revealed the formation of a hydroxyapatite (HA) coating layer after 5 days into SBF solution. Fourier transform infrared spectroscopic (FTIR) analyses confirmed that the coating layer has P-O vibration bands characteristic of HA. The in vitro cytotoxicity was evaluated using a direct contact test, minimum essential medium elution test (ISO 10993-5) and MTT assay. Fibers immersed in SBF and their extracts exhibited lower cytotoxicity than the controls not subjected to immersion, suggesting that SBF treatment improves the biocompatibility of the fiber.
\end{abstract}

Keywords: glass fiber, chemical treatment, bioactivity, cytotoxicity

\section{Introduction}

Bioactive glasses can develop a layer of hydroxyapatite (HA) on their surface when in contact with biological fluids or tissues ${ }^{1,2}$. This layer is responsible for promoting a chemical bond between the material and the host tissue, which may help to reduce the material rejection. A well recognized method to test the in vitro bioactivity of ceramic materials consists in their immersion in an aqueous solution Simulated Body Fluid (SBF) which simulates the properties of human plasma for a certain period, and then verify the formation of the hydroxyapatite (HA) layer on the surface of the sample . $^{2}$

The purpose of this work was to assess the in vitro bioactivity and cytotoxicity of $\mathrm{FM}^{\circledR}$ glass fibers treated with tetraethoxysilane (TEOS) and SBF. The fibers used here present the advantage to be easily purchased in different mesh sizes and can be tested as a framework model regarding the formation of neo tissue. It is important to note that commercial bioactive fibers are not available and for future purposes the use of fibrous materials was desirable since the presence of high porosity is one of the basic requirements for a good vascularization and subsequent growth of neo-bone. This evaluation is part of a process to validate the usefulness of the fiber in the biomedical therapy.

*e-mail: angelala01@ @otmail.com

Article presented at the II SBPMat, Rio de Janeiro - RJ, 26-29 de Outubro/ 2003

\section{Materials and Methods}

The commercial glass fiber $\left(\mathrm{FM}^{\circledR}\right)$ used as a substrate in this study was kindly granted by Athenas, Brazil, a representative of Culimeta Textile Glass Technology (Germany). Disks of $13 \mathrm{~mm}$ in diameter and $50 \mathrm{mg}$ of weight were ultrasonically washed with $0.1 \mathrm{~N} \mathrm{HCl}$ and rinsed with distilled water. After the cleaning step, the disks were dried at $25^{\circ} \mathrm{C}$ under ambient condition and the samples were separated in two groups. One group was not chemically treated and was used as control. The other samples were carefully placed into tetraethoxysilane (TEOS) in polyethylene vials at room temperature for $1 \mathrm{~h}$. The TEOS was then eliminated by filtration and the treated samples were rinsed with ethanol. The samples from the control group were also rinsed under these same conditions. Next, individual samples of the fibers were placed in polyethylene vials with simulated body fluid (SBF) solution and maintained in a water bath at $37{ }^{\circ} \mathrm{C}$. A sample weight/volume of solution with ratio of $0.002 \mathrm{~g} / \mathrm{cm}^{3}$ was used in each experiment. Incubation periods of 5 and 10 days in triplicate samples were used. During the incubation period, the SBF solution was replaced by freshly prepared SBF solution at $48 \mathrm{~h}$ intervals. This procedure was used to avoid microorganism proliferation and also to keep the $\mathrm{pH}$ close to 7.3. The formation of the hydroxyapatite (HA) layer was 
monitored through Fourier transform infrared spectroscopy (FTIR) using a spectrometer model Bomen MB-100C23. Microstructure analyses were also used to follow growth of the HA layer. The scanning electron microscopy analysis (SEM) of samples were performed using a microscope JEOLJSM 840A. The chemical compositions of the FM ${ }^{\circledR}$ fiber was established by X-ray fluorescence (Rigaku GEIGER FLEX).

Cytotoxicity of samples before and after chemical treatment in TEOS and immersion in SBF solution, was deter-

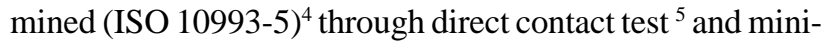
mum essential medium elution test ${ }^{6}$. In these assays, triplicates of sterilized samples, negative (HD polyethylene) and positive (latex) controls or their extracts were carefully placed on a near-confluent monolayer of L-929 mammalian fibroblast cells. The material was incubated at $37{ }^{\circ} \mathrm{C}$ for 24 and $48 \mathrm{~h}$, respectively, in a humidified incubator containing $5 \% \mathrm{CO}_{2}$. After this period, the samples were removed and the cultures examined under a microscope using a histological stain such as $2 \%$ crystal violet in $20 \%$ ethanol to detect morphological alterations, reduction in the cell layer density and cell lysis induced by the tested material. The cellular viability of the extracts was determined in L-929 fibroblast through the MTT assay ${ }^{7}$.

\section{Results and Discussion}

The commercial glass fiber $\left(\mathrm{FM}^{\circledR}\right)$ chemical composition was evaluated by $\mathrm{X}$-ray fluorescence analyses and showed that the fiber contains $\mathrm{Al}_{2} \mathrm{O}_{3}(68,4 \%)$ and $\mathrm{SiO}_{2}$ $(27,6 \%)$ as major components, and $\mathrm{CaO}, \mathrm{TiO}_{2}, \mathrm{Fe}_{2} \mathrm{O}_{3}$ and $\mathrm{CuO}$ as minor components. Commercial fibers present lower silica and calcium contents and display a large amount of aluminum, which is not present in Bioglass ${ }^{\circledR}$ - developed by Hench et al. ${ }^{8}$ that contains $45 \% \mathrm{SiO}_{2}, 24.5 \% \mathrm{CaO}, 24.5 \%$ $\mathrm{Na}_{2} \mathrm{O}$ and $6 \% \mathrm{P}_{2} \mathrm{O}_{5}$.

The FTIR spectra of FM ${ }^{\circledR}$ before treatments (Fig. 1a) reveal peaks near 1080,800 and $460 \mathrm{~cm}^{-1}$, that correspond to the vibrational mode of the asymmetric stretch of $\mathrm{Si}-\mathrm{O}-\mathrm{Si}$, symmetric stretch of $\mathrm{Si}-\mathrm{O}$, and bending of $\mathrm{Si}-\mathrm{O}-\mathrm{Si}$, respectively ${ }^{9}$. Besides these peaks, the $\mathrm{FM}^{\circledR}$ spectrum depicts stretching signals of Al-O-Al in the region $730-620 \mathrm{~cm}^{-1}$. The data sustain the formation of $\mathrm{Si}-\mathrm{O}-\mathrm{Si}$ and $\mathrm{Al}-\mathrm{O}-\mathrm{Al}$ in the fiber, but no evidence of $\mathrm{Si}-\mathrm{O}-\mathrm{Al}$ bonds, thus favoring the non-homogeneous and biphasic nature of the $\mathrm{FM}^{\circledR}$ fiber ${ }^{10}$. After TEOS treatment, the $1160,1110,800$ and $460 \mathrm{~cm}^{-1}$ absorption bands still support the presence of the Si-O-Si bonds ${ }^{9,10}$ and peaks at 960 and $550 \mathrm{~cm}^{-1}$ associate with a $\mathrm{Si}-\mathrm{OH}$ bond and the siloxane backbone vibrations, respectively ${ }^{11}$ (Fig. 1b). The spectra for samples chemically treated and immersed in SBF showed in addition to peaks of Si-O-Si bond near 810, 670, and $460 \mathrm{~cm}^{-1}$, additional peaks at 598, 1060 due to $\mathrm{P}-\mathrm{O}$ bonds (P-O asymmetric stretch $)^{12}$. These absorption bands are a characteristic of hydroxyapatite (Fig. 1c).
Micrographs obtained by SEM analysis show that the distance between fibers varies from 10 to $20 \mu \mathrm{m}$ and their average diameter estimated to be around $5 \mu \mathrm{m}$ (Fig. 2a). After 10 days of immersion in SBF, the sample micrographs, chemically treated (Fig. 2b) revealed the formation of a coating on some surface areas. These results are in agreement with those obtained from FTIR data, and confirm the presence of HA on the fibers after immersion.

The influence of fibers immersion in SBF solution on their cytotoxicity was successfully evaluated. The statistical analysis of the data obtained by direct contact test (Fig.3) showed that the treatment with SBF and the consequent formation of a HA coating reduced significantly $(p<0.05$, " $t$ " Test by Student-Mann-Whitney) the cytotoxicity of FM ${ }^{\circledR}$ fibers. The causes for the increases (no significant) in the cytotoxicity peak for sample FM + TEOS + 10 days in SBF compared to 5 days group, are probably related with an excess of saline ions on the surface of fibers. EDS analysis (not shown) confirms the presence of $\mathrm{NaCl}$ on surface fibers for immersion times higher than 5 days.

The elution test, a qualitative assay, demonstrated a reduction of reactivity of $\mathrm{FM}^{\circledR}$ fibers after exposition to TEOS and SBF (Table 1). This treatment also promoted increase in cellular viability measured by a quantitative test (MTT assay) (61\% - untreated, 68\% - treated fiber). These cytotoxicity levels were relatively low and compatible with international standards ${ }^{5,6}$. These findings support further studies with $\mathrm{FM}^{\circledR}$ fibers using animals models, in order to gain insight into the material behavior within the organism.

\section{Conclusions}

This study shows that the $\mathrm{FM}^{\circledR}$ fiber when chemically

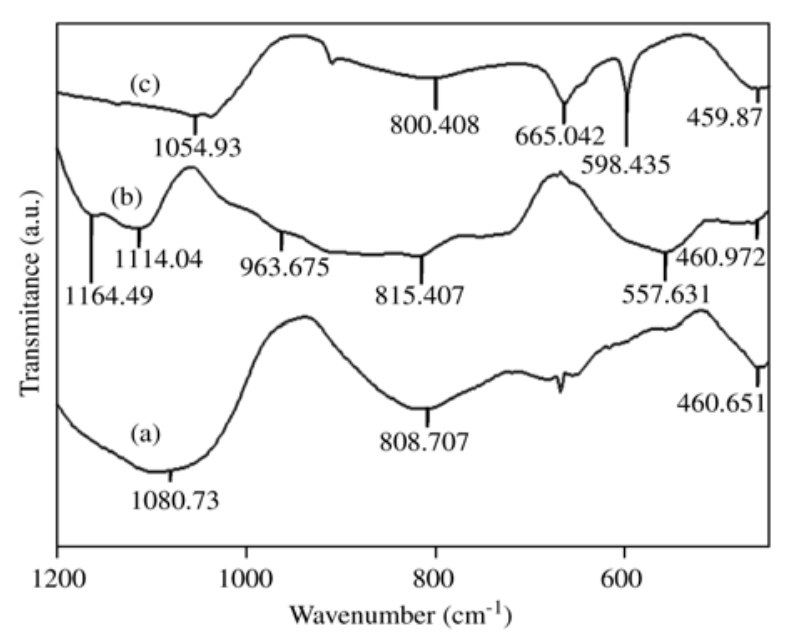

Figure 1. FTIR spectra of FM $^{\circledR}$ fibers: a) before any chemical treatment, b) after TEOS treatment, c) FM after TEOS treatment and immersed for 10 days in SBF solution. 
treated with TEOS and exposed to SBF, is able to form HA coating on its surface. A preliminary evaluation shows that the cytotoxicity is significantly reduced when fibers are

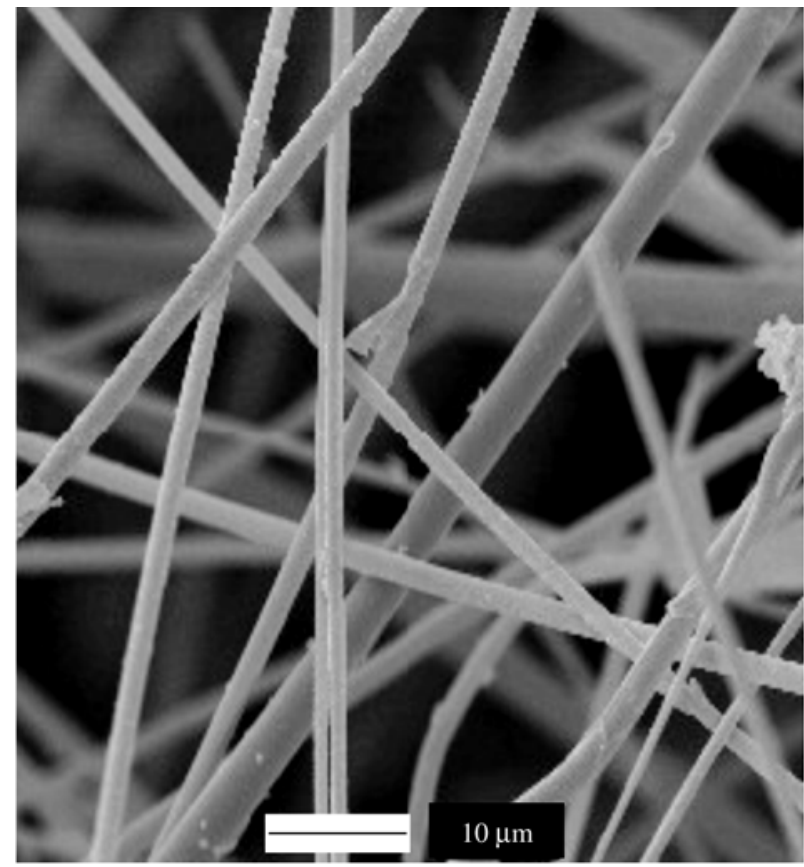

(a) submitted to SBF immersion, suggesting that this could be a simple procedure to minimize implant rejection, thus improving its performance.

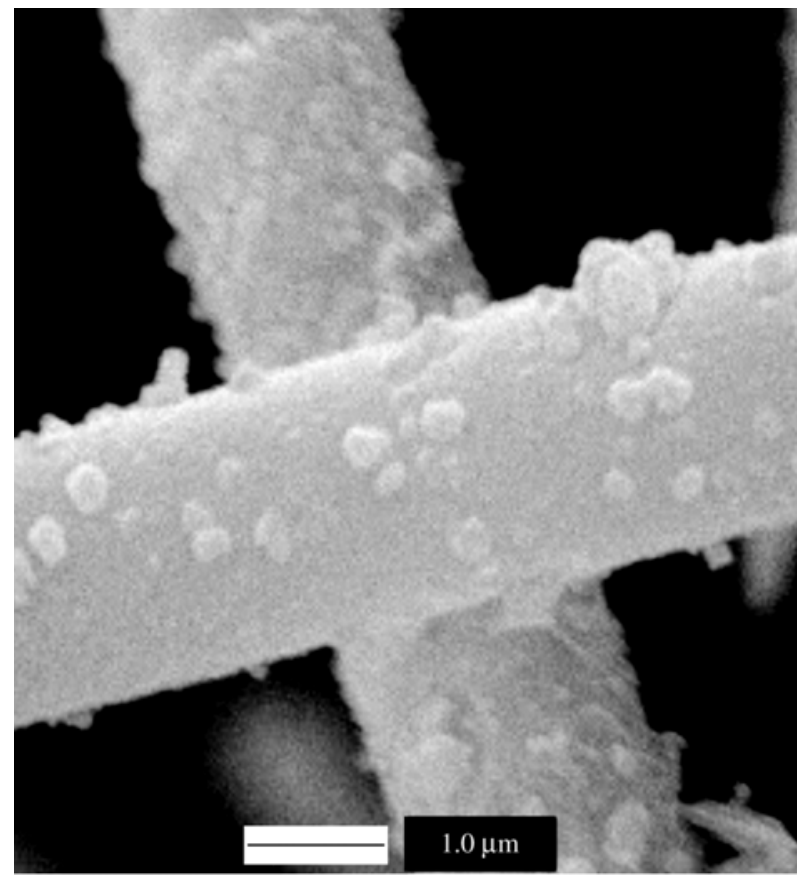

(b)

Figure 2. SEM micrographs of FM ${ }^{\circledR}$ fibers: a) before any chemical treatment, b) after TEOS treatment and immersed for 10 days in SBF solution.

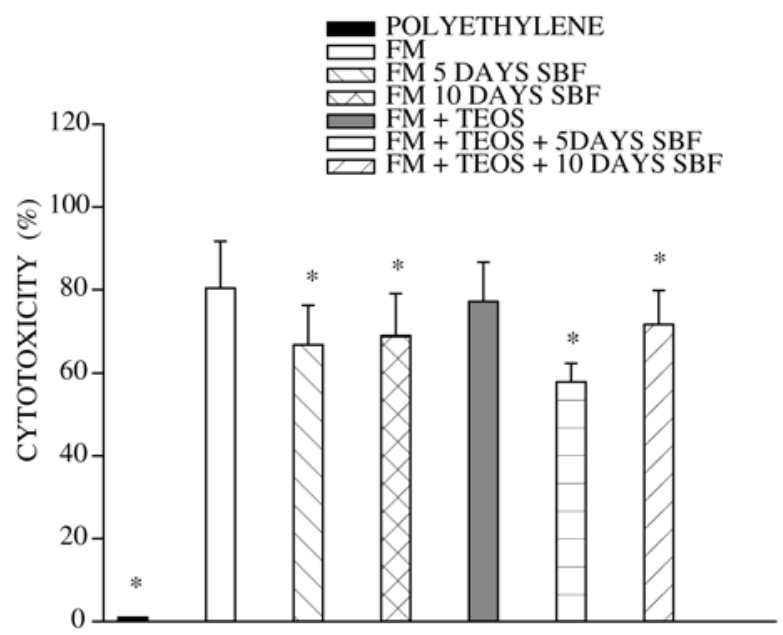

Figure 3. Cytotoxicity of $\mathrm{FM}^{\circledR}$ glass fibers submitted to different treatments. Dotted lines show cytotoxicity of Latex (100\%). High Density Polyethylene was used as negative control. Each value is a mean \pm SEM from 6-9 samples. The fibers $(F M ®)$ treated ir bit with tetraethoxysilane (TEOS) were immersed during 5 and 10 days in Simulated Body Fluid (SBF). Statistical analysis: "t” Test by Student-Mann-Whitney. *Values are significantly different $(\mathrm{p}<0.05)$.
Table 1. Fiber Max (FM $\left.{ }^{\circledR}\right)$ cytotoxicity determined by Elution Test USP-23.

\begin{tabular}{lc}
\hline Material & Reactivity degree \\
\hline HD Polyethylene & 0 \\
Latex & 3 \\
FM $^{\circledR}$ & 2 \\
FM $^{\circledR}$ immersed in SBF for 5 days & 1 \\
FM $^{\circledR}$ immersed in SBF for 10 days & 1 \\
FM $^{\circledR}$ treated with TEOS & 1 \\
FM $^{\circledR}$ treated with TEOS & \\
and immersed in SBF for 5 days & 1 \\
FM $^{\circledR}$ treated with TEOS & \\
and immersed in SBF for 10 days & 1 \\
\hline
\end{tabular}

The fibers $\left(\mathrm{FM}^{\circledast}\right)$ treated or not with tetraethoxysilane (TEOS) were immersed during 5 and 10 days in a simulated body fluid (SBF) solution, before they have their Reactivity degree determined. High Density (HD) Polyethylene was used as negative control and Latex as positive control, $(n=6)$. 


\section{Acknowledgments}

The authors acknowledge the financial support provided by CNPq, FAPEMIG and CAPES.

\section{References}

1. Hench, L.L. Journal of the American Ceramic Society, v. 74, n. 7, p. 1487-1510, 1991.

2. Kokubo, T. in: Handbook of bioactive ceramics, v. 1, Boca Raton, Florida, p. 41-49, 1990.

3. Kokubo, T.; Kushitani, H.; Sakka, S.; Kitsugi, T.; Yamamuro, T. Journal of Biomedical Materials Research, v. 24, n. 6, p. 721-734, 1990.

4. ISO Biological evaluation for medical devices tests for cytotoxicity in vitro methods International Standards Organization, ISO/10993-5, Geneve, Switzerland, 1992.

5. Standard Practice for Direct Contact Cell Evaluation of Materials for Medical Devices, Annual Book ASTM Standard, Medical Devices and Services, Philadelphia, p. 233-236, 1995.
6. US Pharmacopeia. Biological reactivity tests, in vitro. In United States Pharmacopeia, USP - XXIII, United States Pharmacopeial Convention Inc., Rockville, MD, p. 1697-1699, 1995.

7. Bellamy, W.T. Drugs, v. 44, n. 5, p. 690-708, 1992.

8. Hench, L.L.; Splinter, R.J.; Allen, W.C.; Greenlee, T.K. Journal Biomedical Material, Research Symp, v. 36, p. 117-141, 1971.

9. Izquierdo-Barba, I.; Salinas, A.J.; Vallet-Regí, M.; Journal of Biomedical Materials Research, v. 47, n. 2, p. 243-250, 1999.

10. Padmaja, P.; Anilkumar, G.M.; Mukundan, P.; Aruldhas, G.; Warrier, K.G.K. International Journal of Inorganic Materials, v. 3, n. 7, p. 693-698, 2001.

11. Yoshino, H.; Kamiya, K.; Nasu, H. Journal of Non-Crystalline Solids, v. 126, n. 1-2, p. 68-78, 1990.

12. Varma, H.K.; Yokogawa, Y.; Espinosa, F.F.; Kawamoto, Y.; Nishizawa, K.; Nagata, F. Kameyama, T. Journal of Materials Science-Materials in Medicine, v. 10, n. 7, p. 395-400, 1999. 